\title{
On the presence of equatorial waves in the lower stratosphere of a general circulation model
}

\author{
P. Maury and F. Lott \\ Laboratoire de Météorologie Dynamique, UMR8539, IPSL, CNRS/ENS/UPMC/École Polytechnique, Paris, France \\ Correspondence to: P. Maury (pmaury@lmd.ens.fr)
}

Received: 21 May 2013 - Published in Atmos. Chem. Phys. Discuss.: 30 August 2013

Revised: 10 January 2014 - Accepted: 13 January 2014 - Published: 18 February 2014

\begin{abstract}
To challenge the hypothesis that equatorial waves in the lower stratosphere are essentially forced by convection, we use the LMDz atmospheric model extended to the stratosphere and compare two versions having very different convection schemes but no quasi-biennial oscillation (QBO). The two versions have realistic time mean precipitation climatologies but very different precipitation variabilities. Despite these differences, the equatorial stratospheric Kelvin waves at $50 \mathrm{hPa}$ are almost identical in the two versions and quite realistic. The Rossby gravity waves are also very similar but significantly weaker than in observations. We demonstrate that this bias on the Rossby gravity waves is essentially due to a dynamical filtering occurring because the model zonal wind is systematically westward. During a westward phase of the QBO, the ERA-Interim Rossby gravity waves compare well with those in the model.

These results suggest that (i) in the model the effect of the convection scheme on the waves is in part hidden by the dynamical filtering, and (ii) the waves are produced by other sources than equatorial convection. For the Kelvin waves, this last point is illustrated by an Eliassen and Palm flux analysis, showing that in the model they come more from the subtropics and mid-latitude regions, whereas in the ERAInterim reanalysis the sources are more equatorial. We show that non-equatorial sources are also significant in reanalysis data sets as they explain the presence of the Rossby gravity waves in the stratosphere. To illustrate this point, we identify situations with large Rossby gravity waves in the reanalysis middle stratosphere for dates selected when the stratosphere is dynamically separated from the equatorial troposphere. We refer to this process as a stratospheric reloading.
\end{abstract}

\section{Introduction}

In the equatorial stratosphere, the dominant modes of the synoptic-scale variability are the Rossby gravity waves (RGWs) and the Kelvin waves (KWs) first observed in soundings by Yanai and Maruyama (1966) and Wallace and Kousky (1968) respectively. These planetary-scale waves induce perturbations on the horizontal wind of a few metres per second and on temperature of a few Kelvin. These values are larger than the intra-seasonal standard deviation of these fields (Lott et al., 2009). The KWs and RGWs also contribute significantly to the forcing of the quasi-biennial oscillation (QBO) (e.g. Holton and Lindzen, 1972; Baldwin et al., 2001; Tindall, 2006; Ern and Preusse, 2009, among others) and to the dehydration of the air at the tropical tropopause (Jensen et al., 2001; Fujiwara et al., 2001).

The stratospheric equatorial waves (SEWs) are generally considered to be forced by tropical convection (Manzini and Hamilton, 1993; Pires et al., 1997; Lindzen, 2003; Randel and $\mathrm{Wu}, 2005)$, and then to propagate freely above their convective sources. They are distinct from the convectively coupled equatorial waves (CCEWs) in the troposphere (Wheeler and Kiladis, 1999; Straub and Kiladis, 2003; Cho et al., 2004), which are slower than the SEWs and correspond to small vertical wavelengths in the stratosphere where they dissipate rapidly. Despite this difference, these two types of waves are sometimes related (Hendon and Wheeler, 2008), and stratospheric KWs often accompany the life cycle of convectively coupled KWs (Maury et al., 2013). This illustrates that the organisation of convection plays a role as shown by Garcia and Salby (1987) and Randel and Wu (2005), but there is today more and more evidence that the filtering by the background flow largely affects the relationship between 
the stratospheric waves and their convective sources (Alexander and Ortland, 2010). An example is provided in Ern et al. (2009), who show that a large part of the variations in Kelvin wave variances in the stratosphere can be explained by the wind filtering acting over a fixed tropospheric source.

As the large-scale equatorial waves can have small vertical wavelengths in the stratosphere, the general circulation models (GCMs) have difficulties in simulating some of them. This is critical for the RGWs with vertical wavelengths of a few kilometres (Boville and Randel, 1992). Also, the GCMs are inconsistent between them when it comes to representing the equatorial convection variability, and this can yield large differences in the resolved SEWs (Horinouchi et al., 2003). This result needs to be further analysed because the models used by Horinouchi et al. (2003) not only differ by their convection schemes. As a consequence, the differences found between SEWs cannot be directly attributed to the convection scheme used. In a complementary approach Ricciardulli and Garcia (2000) used only one model and showed that changes in the convection scheme strongly impact the KWs and RGWs. Nevertheless, the vertical resolution of the GCM used did not allow them to extend this result to the stratosphere.

The present paper analyses the equatorial waves in the LMDz GCM (Hourdin et al., 2006) extended to the stratosphere (Lott et al., 2005) with two drastically different convection schemes: the Tiedtke (1989) and the Emanuel (1991) schemes. One important aspect of the present work is that the two schemes have been used in Coupled Model Intercomparison Project (CMIP) experiments with LMDz, and, thus, they both have been tuned to provide realistic seasonal mean precipitation climatologies. As we will see, the intraseasonal precipitation variabilities are nevertheless very different. The novelty of the present work is that we can analyse the impact of these differences on SEWs in two simulations with realistic mean climatologies. We will show that the differences moderately impact the equatorial waves in the model stratosphere, which contradicts the study of Horinouchi et al. (2003), at least concerning the planetary-scale waves. This result is nevertheless consistent with Maury et al. (2013), who have shown that the LMDz model simulates stratospheric KWs while its convective variability is underestimated. To interpret this result and to validate the SEWs in the model, we will then locate the sources of the waves in the model and determine if these sources are realistic.

The plan of the paper is as follows. Section 2 introduces the various data sets, and compares the precipitation variabilities between the two model versions and the observations. Section 3 presents a spectral analysis to characterise the precipitation variability and the presence of KWs and RGWs coupled to the convection. We then analyse the KWs and the RGWs in the lower stratosphere via a spectral analysis in Sect. 4, and a composite analysis in Sect. 5. To interpret the origin of the waves in the model, Sect. 6 presents Eliassen and Palm (1961) flux (EP flux) diagnostics for the KWs. As the EP flux appears to be small for the RGWs, Sect. 6 tries to interpret the origin of the RGWs in the model via a composite analysis from the reanalysis data using a different scenario. Section 7 summarises and discusses the results.

\section{Data sets and precipitation climatologies}

\subsection{Model description and data sets}

In this study we use the LMDz grid point model (Hourdin et al., 2006) extended to the stratosphere by Lott et al. (2005). In all the simulations analysed, the resolution in longitude is $\Delta \phi=2.5^{\circ}$ and in latitude $\Delta \lambda=3.75^{\circ}$. The model has 50 vertical levels, with a top at about $70 \mathrm{~km}$, and a vertical resolution of about $1 \mathrm{~km}$ in the lower stratosphere and of about $2 \mathrm{~km}$ in the lower mesosphere. The model also includes orographic and non-orographic gravity wave drag (Lott and Miller, 1997; Hines, 1997) but does not simulate a QBO. A version with 80 vertical levels and a QBO also exists (Lott et al., 2012), but it has not been tested with the Tiedtke (1989) scheme. In this paper, LMDz is used with the two drastically distinct convection schemes according to Tiedtke (1989) and Emanuel $(1991,1993)$, with the model sensitivity to each parameterisation described in Hourdin et al. (2006). Both simulations are forced by sea surface temperature, sea-ice cover, ozone and carbon dioxide that vary annually corresponding to the 1985-2005 period.

For each simulation, a $20 \mathrm{yr}$ long simulation is used, and we refer to each as LMDz-T and LMDz-E for the Tiedtke (1989) and Emanuel (1991, 1993) scheme respectively.

To validate our results, we use the daily precipitation from the Global Precipitation Climatology Project (GPCP) (Adler et al., 2003) over the period 1997-2008, and the daily horizontal wind and temperature from the ERA-Interim (ERAI) reanalysis (Dee et al., 2011) over the period 1989-2009. We consider that the ERAI fields represent well the equatorial waves in the stratosphere, which is supported by comparison with satellite data for the temperature at zonal wave numbers below $s=10$ in Ern et al. (2008). Note that in the present study the daily fields from LMDz and ERAI are interpolated to the six pressure levels in the stratosphere: 100, 70, 50, 30, 20 , and $10 \mathrm{hPa}$.

To characterise the convective activity, we could have used the outgoing long-wave radiation (OLR) data sets as done in many studies to cover a longer period than the GPCP data (e.g. Liebmann and Hartmann, 1982; Wheeler and Kiladis, 1999; Hendon and Wheeler, 2008). However, in LMDz we found that the OLR and the precipitation are not as well correlated as in observations, so we use in the present study the precipitation (i.e. the more direct proxy of convective activity). Note also that OLR LMDz spectra can be found in Maury et al. (2013) for the Emanuel scheme (1991, 1993). 

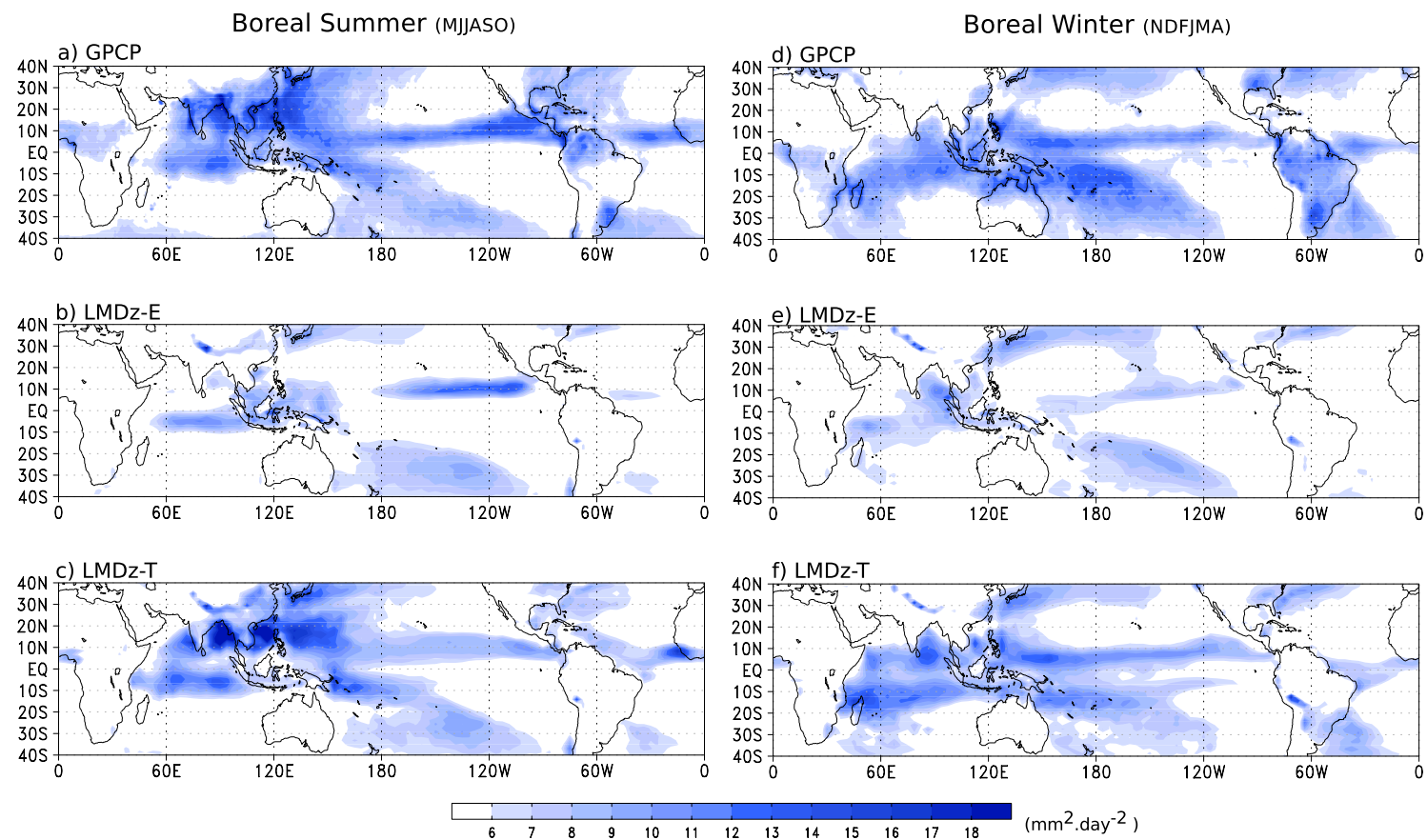

Fig. 1. Standard deviations of precipitation $\left(\mathrm{mm} \mathrm{day}^{-1}\right)$ in boreal summer (May to October: MJJASO, left panels) and boreal winter (November to April: NDJFMA, right panels): (a, d) GPCP (1997-2008), (b, e) LMDz-E (20 yr) and (c, f) LMDz-T (20 yr). The white (blue) colours show relatively low (high) values of precipitation.

\subsection{Precipitation climatologies}

The seasonal means of precipitation are very similar and realistic in both simulations as expected since both schemes have been tuned for this purpose (not shown but see Hourdin et al., 2006). This is not the case for the precipitation variabilities as shown by Fig. 1, which represent the standard deviations of the precipitation calculated over 6 months during boreal summer and boreal winter. Figure 1a and d show that in GPCP the variability is strong over the Intertropical and South Pacific convergence zones, and the monsoon regions as expected. Figure 1b and e show that LMDz-E largely underestimates the convective variability in all these regions, whereas Fig. 1c and f show that LMDz-T is more realistic when compared to GPCP (Fig. 1a and d).

\section{The tropospheric equatorial waves}

To characterise the space-time structure of the precipitation variability and to measure the contribution of the CCEWs to this variability, we next proceed to a spectral analysis of the precipitation fields (e.g. Wheeler and Kiladis, 1999; Hendon and Wheeler, 2008 and Lott et al., 2009, among others). For this purpose, we calculate the symmetric and antisymmetric means of the precipitation between the latitudes $10^{\circ} \mathrm{S}$ and $10^{\circ} \mathrm{N}$. For a given field $X(\lambda, \phi, d, y)$, this consists in evaluating the quantities $X_{\mathrm{s}}(\lambda, d, y)$ and $X_{\mathrm{a}}(\lambda, d, y)$ (where the subscripts $s$ and $a$ denote symmetric and antisymmetric com- ponents) over $N_{\phi}$ latitudes:

$$
\begin{aligned}
& \left\langle X_{\mathrm{s}}\right\rangle(\lambda, d, y)=\frac{1}{N_{\phi}} \sum_{\phi=0}^{10^{\circ}}(X(\phi)+X(-\phi)), \\
& \left\langle X_{\mathrm{a}}\right\rangle(\lambda, d, y)=\frac{1}{N_{\phi}} \sum_{\phi=0}^{10^{\circ}}(X(\phi)-X(-\phi)),
\end{aligned}
$$

where the terms $\lambda, \phi, d$, and $y$ correspond to the longitude, latitude, day and year, respectively. To construct the spectra, we next subtract the annual cycle and then extract 360-daylong segments, centred either on 1 July or on 1 January. From each segment we subtract the temporal trend and apply the tapered cosine window according to Tukey (1967). We then evaluate the segment's periodogram by performing a double Fourier transform in both longitude and time. Finally, the spectrum is estimated by averaging the periodograms over the $20 \mathrm{yr}$.

\subsection{Results}

To present the spectra, we use an energy-conserving formalism where the spectra $S(s, \sigma)$ are multiplied by the frequency $\sigma$ (in cycles per day), and are shown as a function of $\log (\sigma)$ and of the wave number $s$ (e.g. Hendon and Wheeler, 2008, and Maury et al., 2013). This semi-log representation and the use of equatorially averaged quantities allows visualising the CCEW signal due to KWs and RGWs without a normalisation by a red background as done by Wheeler and Kiladis 
(1999). The results are presented in Fig. 2 for the symmetric component and in Fig. 3 for the antisymmetric component. We have also superimposed on the spectra in Fig. 2 and Fig. 3 the theoretical dispersion curves of the equatorial waves deduced from the relation,

$\gamma^{1 / 2}(2 v+1)=\gamma \sigma^{2}-s^{2}-\frac{s}{\sigma}$,

where $\gamma=\frac{4 a^{2} \Omega^{2}}{g h}$ is the Lamb parameter, $a, \Omega$ and $g$ being the earth radius, the earth rotation rate and the gravity constant, respectively. In Eq. (3), the characteristic height $h$ is related to the vertical wave number $m$ by

$m^{2}=\frac{N^{2}}{g h}-\frac{1}{4 H^{2}}$,

with $N$ the Brunt-Väisälä frequency and $H$ the scale height of the atmosphere. In Eq. (3), the integer $v$ corresponds to the number of zeros of the meridional wind $v$ between the poles. We impose the convention $\sigma>0$; thus the sign of $s$ provides the direction of wave propagation (i.e. $s>0(s<0)$ for the eastward (westward) direction). For $v=-1$, only the solution $\sigma=s / \sqrt{\gamma}$ corresponding to the KWs needs to be considered.

\subsubsection{Symmetric component}

The power spectrum for the symmetric component of the GPCP precipitation in Fig. 2a is broadband in the two directions of propagation and shows enhanced power in the eastward direction for the periods between $\sigma^{-1}=3$ days and $\sigma^{-1}=10$ days and wave numbers between $s=3$ and $s=10$. This corresponds to the convectively coupled Kelvin wave (CCKW) signature found by Wheeler and Kiladis (1999). In the eastward direction, we also recognise the Madden-Julian oscillation spectral peak for wave number $s=1,2$ and 3, and for period between $\sigma^{-1}=30$ days and $\sigma^{-1}=50$ days. In the westward direction, the GPCP spectrum shows a relative maximum for wave numbers between $s=-1$ and $s=-6$ and for periods $\sigma^{-1} \approx 15-20$ days, associated with the $v=1$ convectively coupled equatorial Rossby waves (Wheeler and Kiladis, 1999). The black lines in Fig. 2a correspond to the dispersion curves from Eq. (3) with $v=-1$ for KWs (eastward direction) and with $v=1$ for Rossby waves (westward direction). The dispersion curves that best match the maxima identified in the Fig. 2a spectrum have equivalent depths in the range of about $h=20 \mathrm{~m}$ and $h=50 \mathrm{~m}$, as expected for the CCEWs (Liebmann and Hendon, 1990; Wheeler and Kiladis, 1999).

The spectra in Fig. $2 b$ and $c$ show that LMDz has difficulties in producing CCEWs, and especially in the eastward direction. More specifically, we can note that LMDz$\mathrm{T}$ produces a small relative maximum for $\mathrm{KWs}$ with periods between $\sigma^{-1}=8$ days and $\sigma^{-1}=20$ days and wave numbers between $s=2$ and $s=6$ (Fig. 2c), which is almost absent from LMDz-E (Fig. 2b). In the westward direction, the
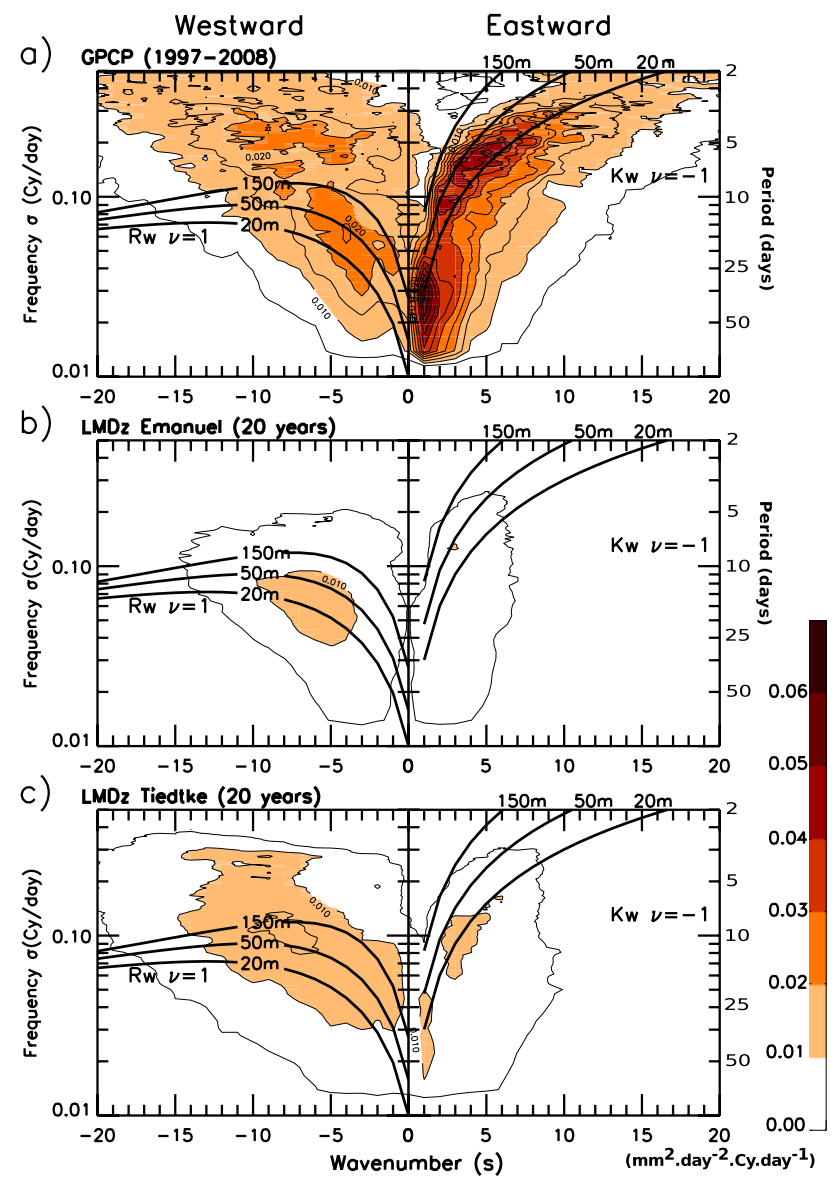

Fig. 2. Wave-number-frequency spectra of the symmetric component of the precipitation averaged over latitude range from $10^{\circ} \mathrm{S}$ to $10^{\circ} \mathrm{N}$ (units are in $\mathrm{mm}^{2} \mathrm{j}^{-2} \mathrm{Cy} \mathrm{j}^{-1}$ ): (a) GPCP, (b) LMDz-E, and (c) LMDz-T. Contour intervals are $0.01 \mathrm{~mm}^{2} \mathrm{j}^{-2} \mathrm{Cy} \mathrm{j}^{-1}$ for the shaded areas and $0.005 \mathrm{~mm}^{2} \mathrm{j}^{-2} \mathrm{Cy} \mathrm{j}^{-1}$ for the thin solid lines. The light (dark) colours show relatively low (high) precipitation spectrum values. The superimposed dispersion curves (thick solid lines) are calculated from Eq. (3) for the KWs $(v=-1)$ in the eastward panels and for the Rossby waves $(v=+1)$ in the westward panels. They are displayed for the three equivalent depths $h=20,50$ and $150 \mathrm{~m}$.

LMDz-T spectrum is stronger in amplitude than the LMDzE spectrum, indicating that the equatorial Rossby waves are better simulated with the Tiedtke (1989) scheme. This difference will not be further analysed, since the equatorial Rossby waves are too slow to penetrate deeply into the stratosphere (Yang et al., 2011).

\subsubsection{Antisymmetric component}

The antisymmetric GPCP precipitation spectrum in Fig. 3a is also broadband in the two directions but presents enhanced power from the wave number $s=-8$ and a period of about $\sigma^{-1} \approx 8$ days in the westward direction until the wave numbers $s=3$ in the eastward direction and a period of about 

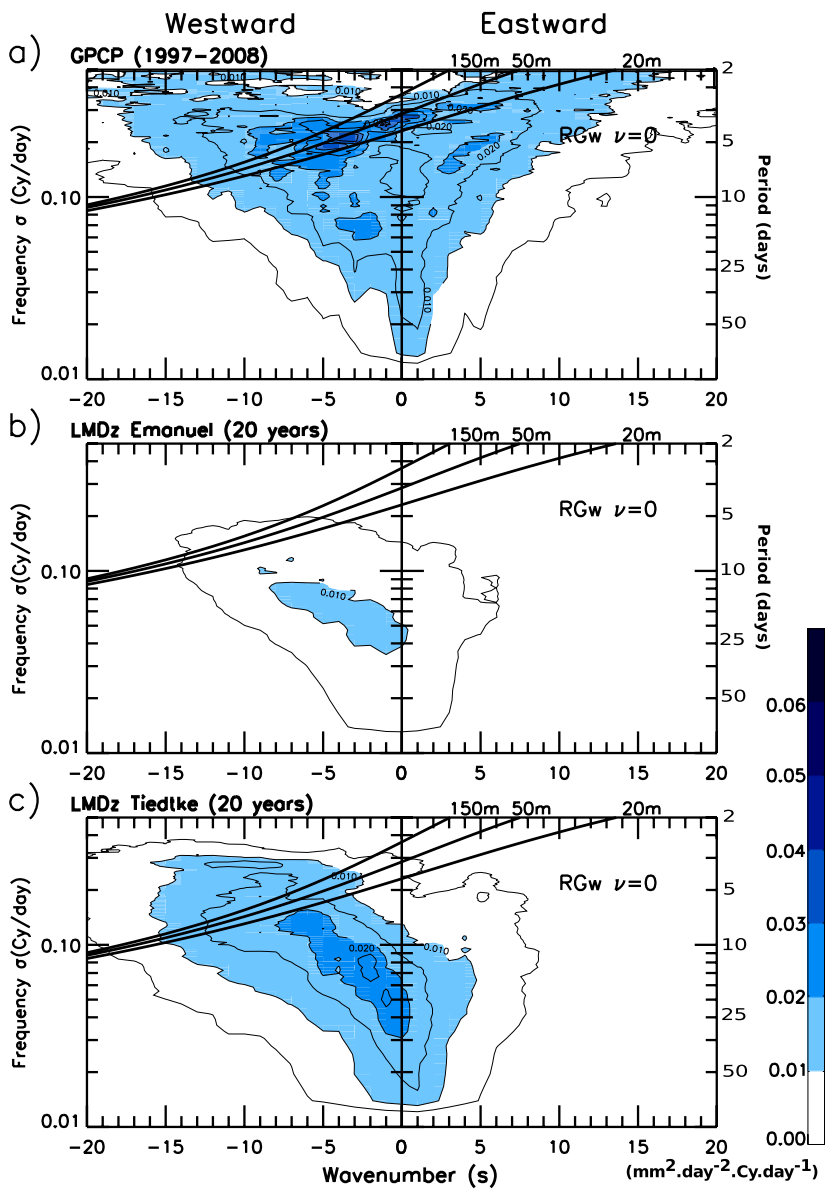

Fig. 3. Same as Fig. 2 except for the antisymmetric component of precipitation. The dispersion curves are calculated for the RGWs $(v=0)$.

$\sigma^{-1}=3$ days. This region lies in the spectral domain of the convectively coupled RGWs (Wheeler and Kiladis, 1999), as indicated by the dispersion curves from Eq. (3) with $v=0$, and for $h=20 \mathrm{~m}$ and $h=50 \mathrm{~m}$. The Fig. $3 \mathrm{~b}$ and $\mathrm{c}$ show that LMDz-E largely underestimates the antisymmetric precipitation variability, whereas LMDz-T is much more realistic in amplitude. Nevertheless, LMDz-T underestimates the eastward signal, and does not show enhanced power corresponding to RGWs. Another essential point with LMDz-T, and to a lesser extent with LMDz-E, is that the antisymmetric spectra (Fig. 3b and c) have larger amplitude than the symmetric ones (Fig. 2b and c). This indicates that the precipitation variability is much less organised over the Equator than in the observations and suggests that LMDz has difficulties in simulating a large-scale organisation of the convection. This defect might be related to the misrepresentation of CCEWs by LMDz.

\section{Stratospheric spectra}

To study the stratospheric equatorial waves, we use the fact that, for the KWs and the RGWs, at least one of the dynamical fields $u, v$ and $T$ does not change sign with latitude in the equatorial band at a given longitude. In the following, the temperature $(T)$ is used to characterise the KWs and the meridional wind $(v)$ for the RGWs.

\subsection{Temperature}

Figure 4 shows the temperature spectra in the lower stratosphere at $z_{p}=50 \mathrm{hPa}$. The ERAI spectrum in Fig. 4a does not differ from the ERA40 spectrum presented in Lott et al. (2009), and consists of a broad maximum for wave numbers between $s=1$ and $s=5$ for periods between 3 and 20 days, which corresponds to the KW packets. This spectral peak occurs at slightly higher equivalent depths than the one attributed to CCKWs in Fig. 2a. This shift to higher equivalent depths means that on average KWs have larger vertical wavelengths (cf. Eq. 4) in the stratosphere than in the troposphere. The reason for the shift is that KWs with shorter vertical wavelengths, having lower phase speeds, are more strongly affected by dissipation processes and critical wind levels.

Figure $4 \mathrm{~b}$ and $\mathrm{c}$ show that the temperature spectra from the model are quite realistic and even larger in amplitude than those from ERAI. This occurs despite the much reduced amplitude of the precipitation spectra in the model, especially in the domain of the CCKWs. To understand this large wave signal, we must mention that the zonal mean zonal wind is always negative (i.e. westward) in the LMDz lower equatorial stratosphere (not shown, but the model does not simulate a QBO), whereas it is negative less than half of the time in observations because of the QBO. In the model stratosphere, the KWs always propagate easily as they have positive phase speed and hence larger positive intrinsic phase speed than during a zero or positive (i.e. eastward) zonal mean wind. This corroborates with Alexander and Ortland (2010), who have shown that the filtering by the zonal wind strongly modulates the relationship between convection and stratospheric waves. Also, from the fact that in LMDz-E the zonal mean zonal wind is more negative than in LMDz-T (not shown), it follows that the KWs are stronger in LMDz-E than in LMDz$\mathrm{T}$.

\subsection{Meridional wind}

Figure 5 presents the meridional wind spectra in the lower stratosphere at $z_{p}=50 \mathrm{hPa}$. The ERAI spectrum in Fig. 5a is dominated by a broad maximum in the westward direction between the wave numbers $s=-4$ and $s=-8$ and the periods $\sigma^{-1}=2$ days and $\sigma^{-1}=8$ days, due to the RGW packets (see Lott et al., 2009, and also the dispersion curves for RGWs calculated from Eq. (3) with $v=0$ ). Once again, 

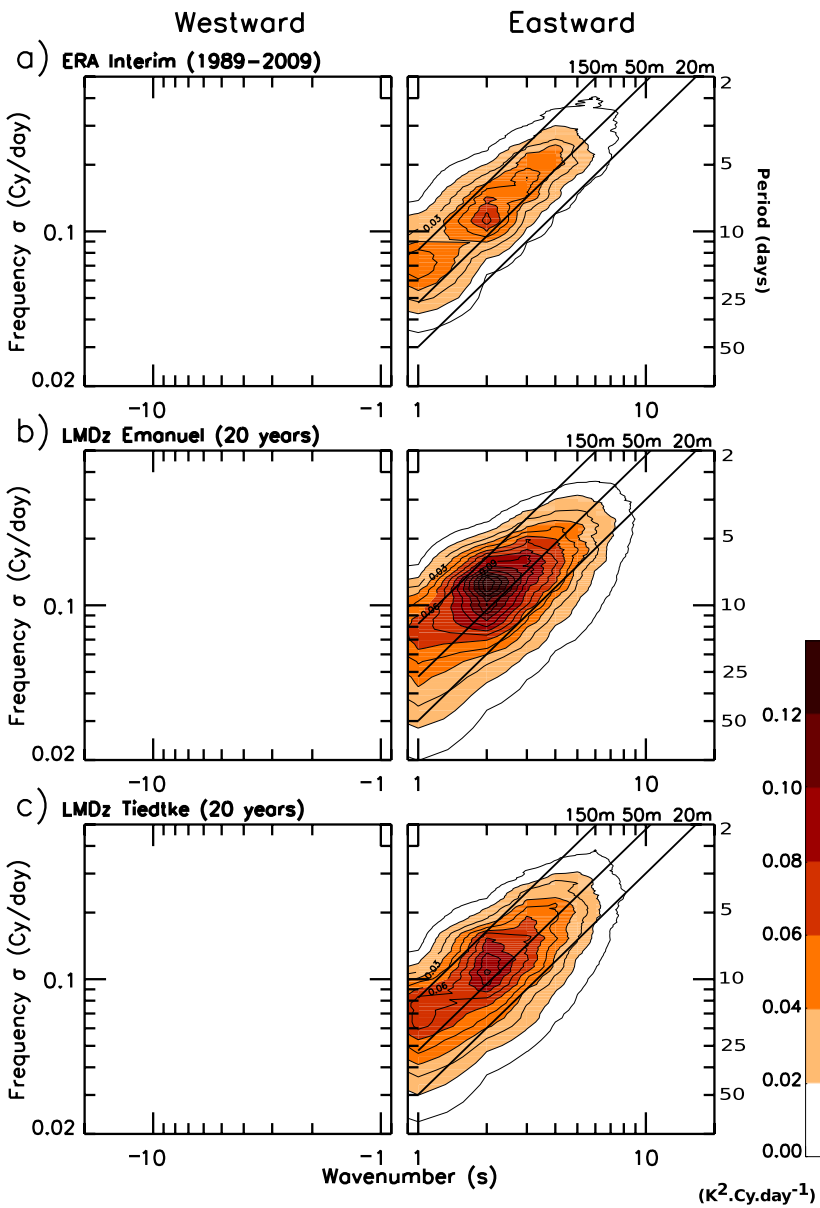

Fig. 4. Wave-number-frequency spectra of the temperature averaged over latitude range from $10^{\circ} \mathrm{S}$ and $10^{\circ} \mathrm{N}$, at $50 \mathrm{hPa}$ (units are in $\mathrm{K}^{2} \mathrm{Cy} \mathrm{j}^{-1}$ ): (a) ERAI, (b) LMDz-E and (c) LMDz-T. Contour intervals are $0.02 \mathrm{~K}^{2} \mathrm{Cy} \mathrm{j}^{-1}$ for the shaded areas and $0.01 \mathrm{~K}^{2} \mathrm{Cy} \mathrm{j}^{-1}$ for the thin solid lines. The light (dark) colours show relatively low (high) spectrum values for the temperature. The dispersion curves (thick solid lines) from Eq. (3) are calculated for KWs $(v=-1)$ with $h=20,50$ and $150 \mathrm{~m}$.

the equivalent depth associated with these waves is higher than for the RGWs in the troposphere.

Figure $5 \mathrm{~b}$ and $\mathrm{c}$ show that the RGW signal is largely underestimated by LMDz, which is again more related to a dynamical filtering than to a deficiency in precipitation variability. Accordingly, the LMDz zonal wind zonal mean is negative in the upper troposphere and lower stratosphere implying that the RGW packets with negative phase speed are more dissipated than in ERAI. The dominant role of the dynamical filtering is further illustrated by the larger RGW signal in LMDz-T than in LMDz-E according to the more negative zonal wind in LMDz-E than in LMDz-T and despite the larger precipitation variability in LMDz-T than in LMDz-E.
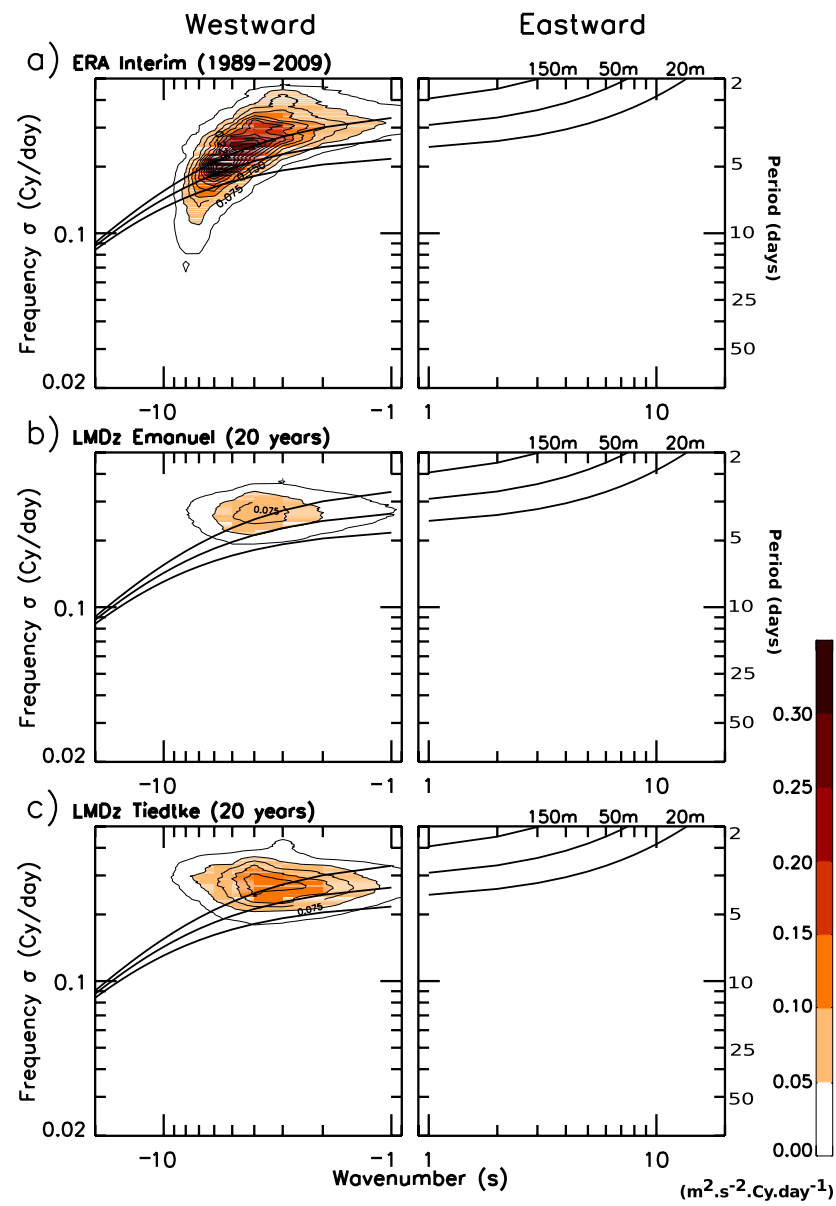

Fig. 5. Wave-number-frequency spectra of the meridional wind averaged over latitude range $10^{\circ} \mathrm{S}$ and $10^{\circ} \mathrm{N}$, at $50 \mathrm{hPa}$ (units are in $\mathrm{m}^{2} \mathrm{~s}^{-2} \mathrm{Cy} \mathrm{j}^{-1}$ ): (a) ERAI, (b) LMDz-E and (c) LMDz-T. Contour intervals are $0.05 \mathrm{~m}^{2} \mathrm{~s}^{-2} \mathrm{Cyj}^{-1}$ for the shaded areas and $0.025 \mathrm{~m}^{2} \mathrm{~s}^{-2} \mathrm{Cy} \mathrm{j}^{-1}$ for the thin solid lines. The light (dark) colours show relatively low (high) spectrum values for the meridional wind. The dispersion curves (thick solid lines) from Eq. (3) are calculated for the RGWs $(v=0)$ with $h=20,50$ and $150 \mathrm{~m}$.

\section{Composite analysis}

To characterise the spatial structure and the life cycle of the SEWs, we follow Lott et al. (2009) and make a composite analysis of band-pass-filtered fields. For the KWs, the bandpass filter operates in the frequency-wave-number Fourier space by multiplying the Fourier components of all fields by a transfer function that largely contains the broadband spectral maxima associated with KWs (Fig. 4), and guarantees that the filtered fields include them well. To finalise the filtering we then return to physical space. To diagnose when a KW is present at $50 \mathrm{hPa}$, we evaluate an index whose value equals the maximum of the filtered temperature averaged between $10^{\circ} \mathrm{S}$ and $10^{\circ} \mathrm{N}$, and identify the longitude $\lambda_{M}$ at which this maximum occurs. The composites are then built from averages over dates when maxima of this index exceed a given 

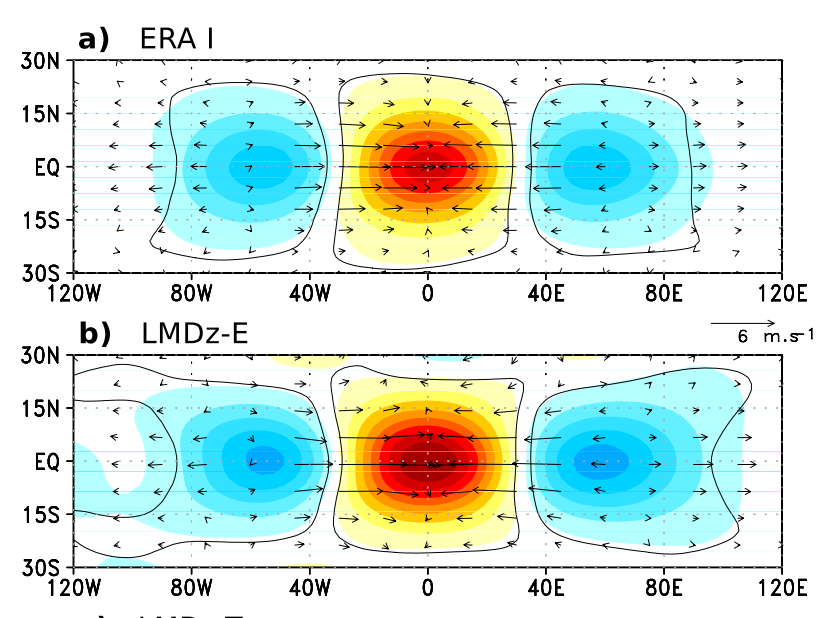

c) $\mathrm{LMDZ}-\mathrm{T}$

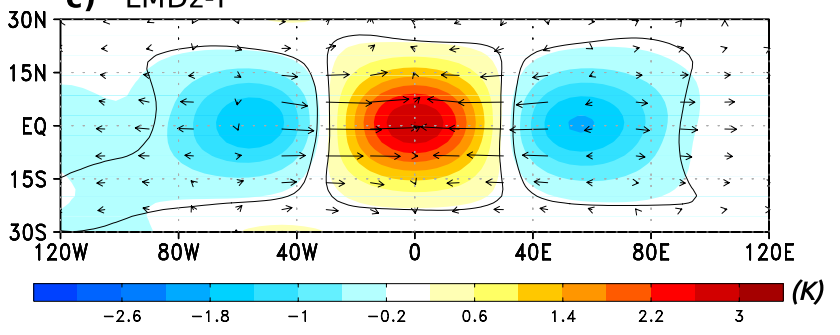

Fig. 6. Longitude-latitude maps for the $\mathrm{KW}$ packet composite at the level $z_{p}=50 \mathrm{hPa}$ and the $l=0$ day lag. The shaded areas are for the temperature $T^{\mathcal{C}}$ (red (blue) colours are for positive (negative) values, in $\mathrm{K})$ and the arrows for the horizontal wind $\left(u \mathcal{C}, v^{\mathcal{C}}\right)$ : (a) ERAI, (b) LMDz-E, and (c) LMDz-T. The black lines delimit the $99 \%$ significant regions according to a Student $t$ test for the temperature.

threshold and shifting the maps selected by $-\lambda_{M}$. We also average the dates at various lags before and after the central dates, so the composites are 41 days long. In each data set the threshold is chosen so that the number of cases selected equals the number of years in the data set. We choose here to select a rather low number of events to guarantee independence between the selected wave packets, bearing in mind that each wave packet can have a life cycle that lasts nearly a month. To ensure that the same wave cannot be selected twice, no day within 20 days after a case event can be selected. Finally, we have tested that none of the results are affected by moderate changes in the thresholds or in the filters (for instance, including more horizontal wave numbers). In the following, the composite of a filtered dynamical fields $X$ is noted $\widetilde{X}^{\mathcal{C}}$.

For the Rossby gravity waves, we follow the same procedure but use a transfer function that contains the westward maxima in Fig. 5 to build the band-pass filter, and use the meridional wind $v$ to define the index.
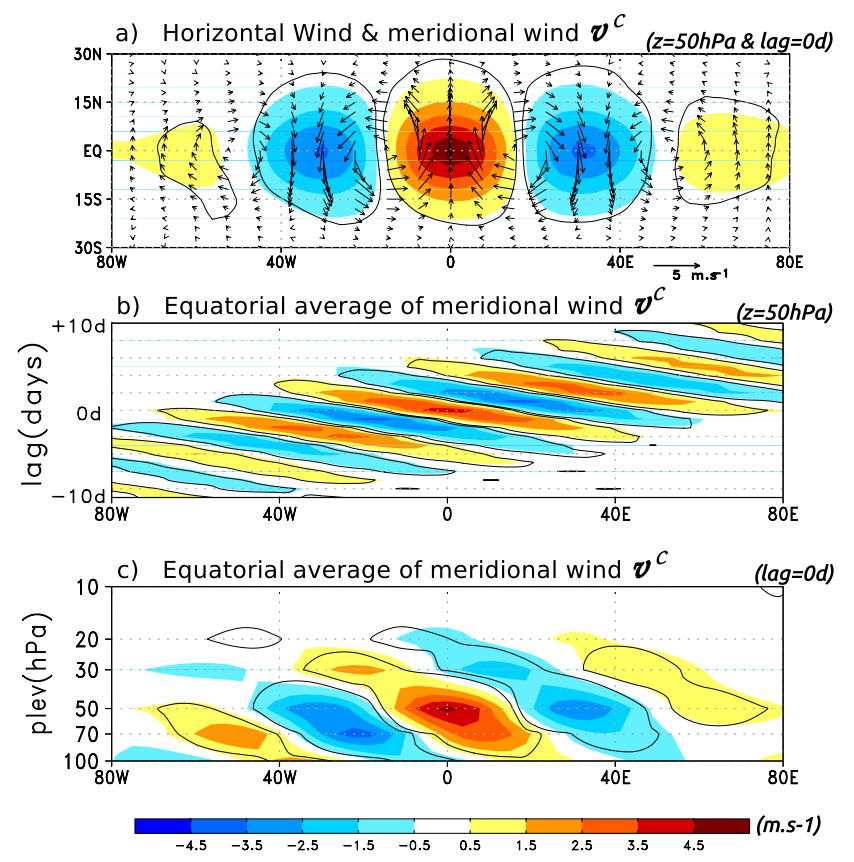

Fig. 7. RGW composites from ERAI: (a) meridional wind $v^{\mathcal{C}}$ (shading) and horizontal wind $\left(u^{\mathcal{C}}, v^{\mathcal{C}}\right)$ (arrows) at $z_{p}=50 \mathrm{hPa}$ and $l=0$ day lag. (b) Hovmöller diagram of the meridional wind $v^{\mathcal{C}}$ at $z_{p}=50 \mathrm{hPa}$. (c) Longitude-altitude cross section of the meridional wind $v^{\mathcal{C}}$ averaged over the equatorial band. Shaded areas of meridional wind values are in red (blue) for positive (negative) $\left(\mathrm{m} \mathrm{s}^{-1}\right)$. The black lines delimit the $99 \%$ significant regions according to a Student $t$ test for the meridional wind.

\subsection{Kelvin waves}

To extract the KW packets, the band-pass filter is defined essentially to keep the eastward propagating disturbances with frequency between $\sigma^{-1}=3$ days and $\sigma^{-1}=10$ days and wave numbers between $s=1$ and $s=6$.

The composites for the horizontal wind $\left(\widetilde{u}^{\mathcal{C}}, \widetilde{v}^{\mathcal{C}}\right)$ and the temperature $\left(\widetilde{T}^{\mathcal{C}}\right)$ in Fig. 6 confirm that we are in the presence of KWs, since (i) the wind perturbations are almost exactly zonal and in quadrature with the temperature perturbations, and (ii) these signals are confined to the equatorial region. Figure 6 also shows that the peak in KW amplitude is larger in the model (Fig. 6b and c) than in ERAI (Fig. 6a), and even slightly larger in LMDz-E than in LMDz-T. As mentioned in Sect. 3, this is consistent with the fact that the dynamical filtering dominates, the zonal wind in the LMDz-E lower stratosphere being more negative than in LMDz-T. In ERAI a filtering by the QBO is also active, since the selected dates occur during the easterly phases of the QBO at $50 \mathrm{hPa}$. During these easterly phases, the winds in ERAI are less negative than in both model simulations, which might explain the smaller amplitude in ERAI composites than in LMDz. As in Lott et al. (2009) and Maury et al. (2013), we also find that the absence of a QBO favours the KW packet propagation up 

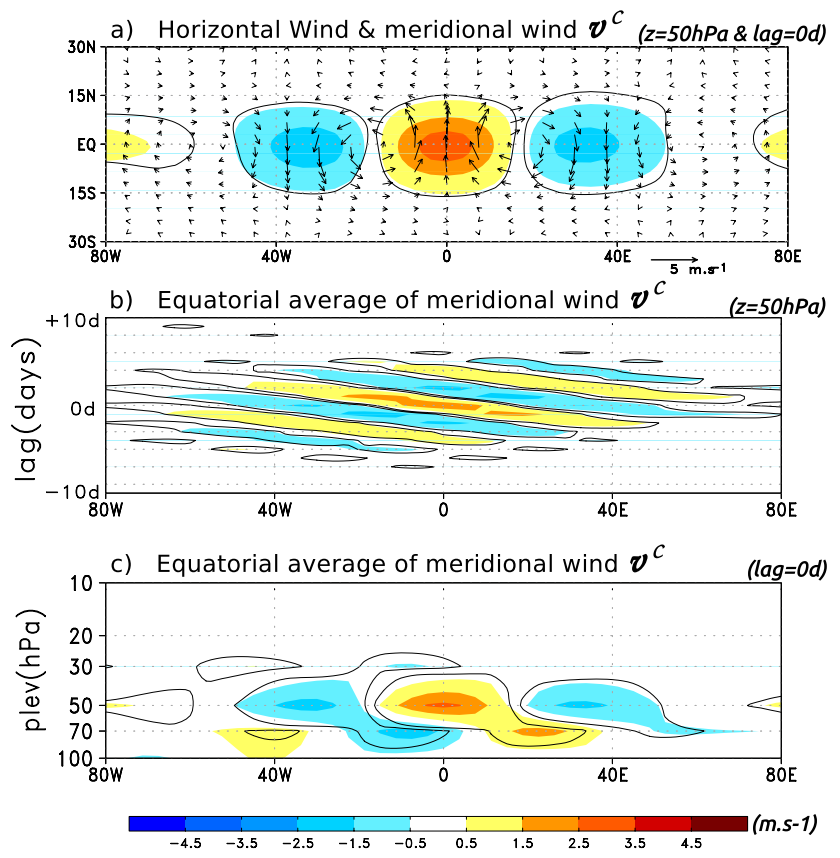

Fig. 8. Same as Fig. 7 for LMDz-E.

to the upper stratosphere, whereas the wave packets in ERAI are attenuated in the region where the $\mathrm{QBO}$ signal is eastward (not shown).

\subsection{Rossby gravity waves}

To extract the RGW packets, the band-pass filter is defined essentially to keep the westward propagating disturbances with frequencies between $\sigma^{-1}=3$ days and $\sigma^{-1}=8$ days and wave numbers between $s=4$ and $s=8$.

The composites of the winds $\left(\widetilde{u}^{\mathcal{C}}, \widetilde{v}^{\mathcal{C}}\right)$, from ERAI (Fig. 7a) and from LMDz-E (Fig. 8a), confirm that we are in the presence of RGWs, since they present a succession of clockwise and anticlockwise circulation centres: (i) centred at the Equator and (ii) confined within the equatorial region. The RGW packets in ERAI (Fig. 7a) are larger than in LMDz-E (Fig. 8a) or LMDz-T (not shown, but the composites are almost identical to those in Fig. 8a). As a first guess, we could attribute the deficit in RGWs in the model to a misrepresentation of the precipitation variability (see Figs. 2 and 3 ). However, several pieces of evidence indicate that the continuous negative zonal wind in LMDz lower stratosphere dynamically filters the RGWs. The first one is given by the longitude-time plots in Figs. $7 \mathrm{~b}$ and $8 \mathrm{~b}$, which show that the negative absolute phase speed of the waves in LMDz is larger in amplitude than in ERAI. In the model, the absolute phase speed of the RGWs needs to be larger to maintain a subsequent negative intrinsic phase speed when the background zonal wind is negative. The second one is given by the zonal-vertical profiles of the RGWs, which show that the RGW packets do not propagate above $30 \mathrm{hPa}$ in the model
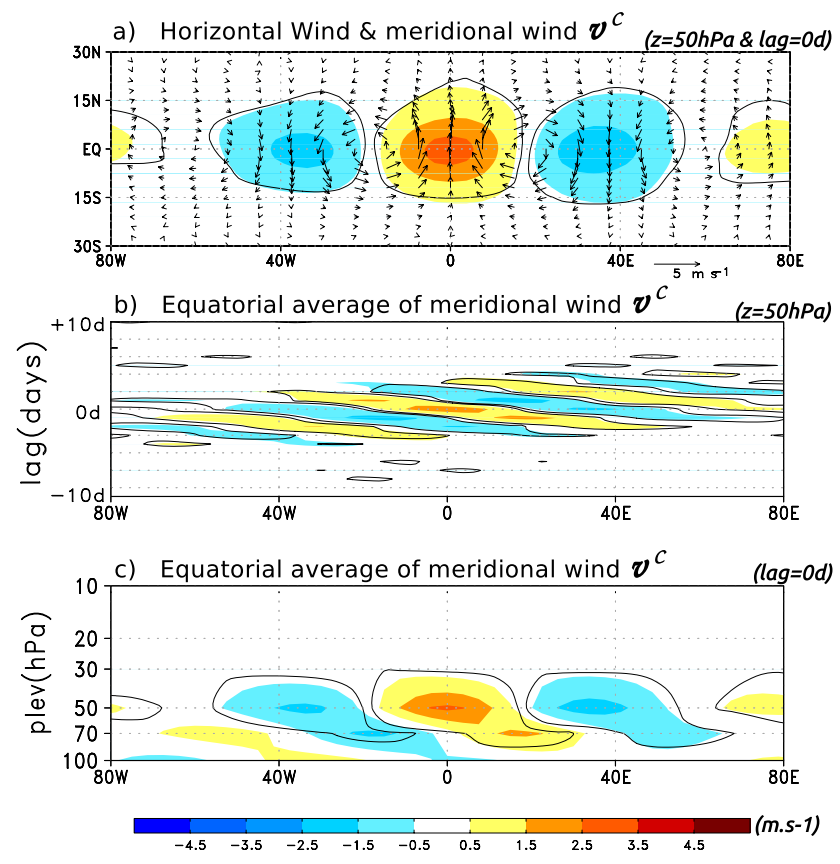

Fig. 9. Same as Fig. 7 for ERAI selecting dates when the zonal mean zonal wind is negative at $50 \mathrm{hPa}$.

(Fig. 8c) compared to those in ERAI (Fig. 7c). The RGW vertical wavelength is smaller in LMDz (Fig. 7c) than in ERAI (Fig. 8c) due to the wind filtering, and is likely too small to be properly resolved by the model.

Finally, we recall here that the composite method only selects dates in the ERAI RGW index during positive QBO phase (cf. Lott et al., 2009). Thus, the LMDz and ERAI RGW composites are not directly comparable. To compare both RGW composites strictly, we perform another composite analysis by picking dates in the ERAI RGW index for negative zonal wind at $50 \mathrm{hPa}$ (i.e. during negative QBO phases). The resulting composites (Fig. 9) are very similar to those from LMDz (Fig. 8). Under such dynamical conditions, the weak amount of RGWs in the reanalysis can be attributed to the wind filtering only. This result is supported by recent work with a new LMDz version with a QBO (Lott et al., 2012), where it is shown that the simulated RGWs are improved with positive zonal wind in the lower stratosphere. It confirms that the model potentially simulates the right amount of RGWs, despite the misrepresentation of the tropospheric convection variability.

\section{On the origin of the equatorial waves in the model}

According to the linear theory, the wave amplitude depends on both the amplitude of the sources and the subsequent filtering. Given the wind filtering, Sect. 5.2 confirms that LMDz simulates realistic stratospheric RGWs and KWs while Sect. 3 shows that the tropospheric convection 
(a) ERA-I

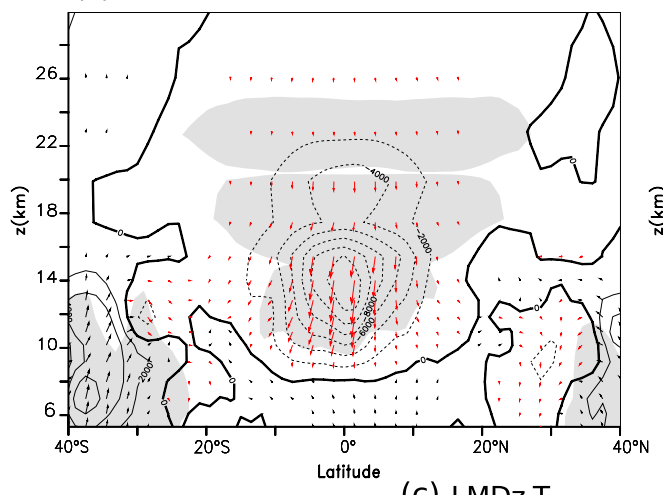

(b) LMDz-E

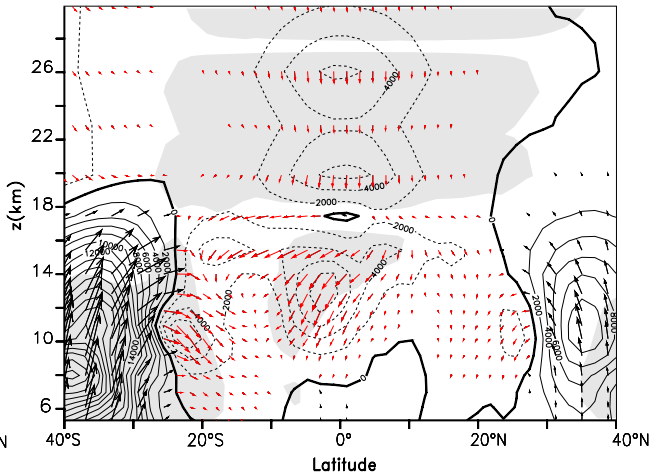

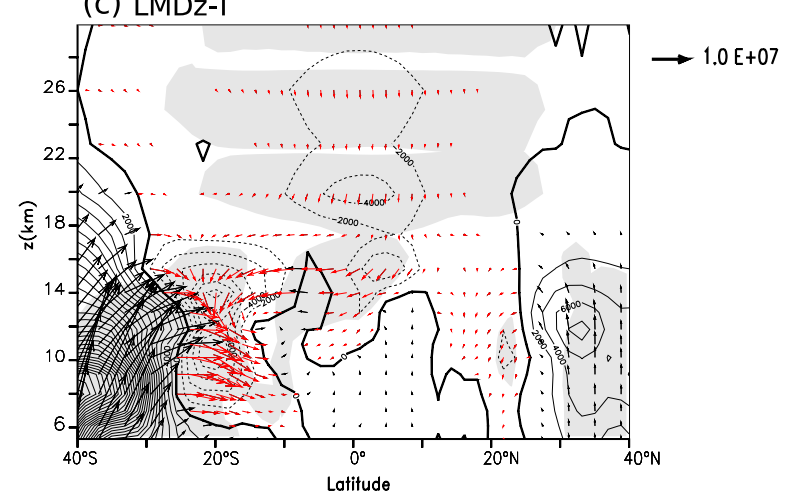

Fig. 10. Composite of the Eliassen-Palm flux vector $\left(\overline{F^{\phi}}, \overline{F^{z}}\right)$ (arrows) and of its vertical component $\overline{F^{z}}$ (contours with negative values dashed, interval of $1000 \mathrm{~Pa}$, red (black) arrows corresponding to negative (positive) vertical component $\overline{F^{z}}$ ): (a) ERAI, (b) LMDz-E, (c) LMDz-T. The grey shaded areas corresponding to the $99 \%$ significant regions of the vertical component of the EP flux according to a Student $t$ test evaluated for the horizontal and vertical wind.

variability is underestimated in the corresponding wavenumber-frequency window. In the linear view, the wave amplitude is directly related to the source amplitude, indicating that the model has other sources than equatorial convection that can be substantial enough to supplement the lack of the convective forcing.

\subsection{EP fluxes due to Kelvin wave composite}

To locate these sources for the KWs, we evaluate the EP flux (Eliassen and Palm, 1961) vector $\overline{\boldsymbol{F}}$ of the KW, adapting Andrews et al. (1987):

$\overline{F^{\phi}}=\rho_{0} a \cos \phi\left(\bar{u}_{z} \frac{\overline{v^{\mathcal{C}} \theta^{\mathcal{C}}}}{\bar{\theta}_{z}}-\overline{u^{\mathcal{C}} v^{\mathcal{C}}}\right)$,
$\overline{F^{z}}=\rho_{0} a \cos \phi\left(\left(f-\frac{(\bar{u} \cos \phi)_{\phi}}{a \cos \phi}\right) \frac{\overline{v^{\mathcal{C}} \theta^{\mathcal{C}}}}{\bar{\theta}_{z}}-\overline{u^{\mathcal{C}} w^{\mathcal{C}}}\right)$.

Here $\bar{u}$ and $\bar{\theta}$ refer to the unfiltered zonal wind and potential temperature respectively. In this context, the composite fields $\widetilde{u}^{\mathcal{C}}, \widetilde{v}^{\mathcal{C}}, \widetilde{w}^{\mathcal{C}}$ and $\widetilde{\theta}^{\mathcal{C}}$ are used as disturbances, which is justified for the filtered fields because none of the band-pass filters used keep the $s=0$ component. For completeness, the reference density is $\rho_{0}(z)=\rho_{r} \exp (-z / H)$, where $\rho_{r}$ is a constant, and the Coriolis parameter $f=2 \Omega \sin \phi$, where $\phi$ is the latitude.

The EP flux vector $\left(\overline{F^{z}}, \overline{F^{\phi}}\right)$ and its vertical component $\overline{F^{z}}$ are presented in Fig. 10. In the reanalysis (Fig. 10a), the EP flux essentially comes from the mid- and high troposphere of the equatorial regions, between $10^{\circ} \mathrm{S}$ and $10^{\circ} \mathrm{N}$ and above $8 \mathrm{~km}$ typically. The EP flux is almost constant up to $15-$ $17 \mathrm{~km}$, suggesting that the KW packet propagates with little dissipation from the upper troposphere to the lower stratosphere. The amplitude decreases rapidly above $18 \mathrm{~km}$ when the KWs dissipate. As observed in LMDz-E (Fig. 10b) and LMDz-T (Fig. 10c), the results from the model are very different, with the KW EP flux coming from regions around $15-20^{\circ} \mathrm{S}$, which are significantly outside of the equatorial regions. The interpretation that convection is not the main driver in LMDz is supported by the fact that the dates used to build the Fig. 10 are selected during the boreal summer (e.g. when the convection is stronger in the Northern Hemisphere subtropics (cf. Fig. 1a, b and c)), whereas the KWs seem to come from the southern subtropics. 


\subsection{Rossby gravity waves: stratospheric reloading}

We tried to conduct a comparable analysis for the RGWs, but the EP flux composites from the model are not significant enough to be conclusive. Note that this smallness of the vertical EP flux is partly an intrinsic difficulty of the westward propagating RGWs that behave as Rossby waves. As a consequence, the RGW vertical EP flux is essentially related to the meridional heat flux term multiplied by the Coriolis parameter (see Eq. 6), implying that the vertical EP flux becomes small near the Equator for these waves.

To circumvent this problem, and illustrate that the extratropical forcing can be significant for the RGWs, we do as in Section 5 and build a scenario where such a forcing operates in the reanalysis. For this purpose we next evaluate a RGW composite at $20 \mathrm{hPa}$, in a configuration where the zonal wind is negative below this level. We know from the results in Sect. 5.2 that during the negative phase of the QBO the RGWs cannot reach $30 \mathrm{hPa}$ (see Fig. 9c). Accordingly, we consider that the RGWs present at $20 \mathrm{hPa}$ during such a phase of the QBO are dynamically separated from their convective sources in the troposphere because of the wind filtering layer below $50 \mathrm{hPa}$. Figure 11a shows the horizontal wind $\left(u^{\prime}, v^{\prime}\right)$ at the lag $l=0$ day and at $20 \mathrm{hPa}$. We recognize the horizontal wind structure characteristic of RGWs, with wind maxima of about $4 \mathrm{~m} \mathrm{~s}^{-1}$. The Hovmöller diagram in Fig. $11 \mathrm{~b}$ indicates that the waves propagate westward with a phase speed $c_{\phi} \approx-19 \mathrm{~m} \mathrm{~s}^{-1}$, which is comparable to the RGW phase speed at $50 \mathrm{hPa}$ in Sect. 5.2. Finally, the vertical structure of the composite in Fig. 11c shows that the RGWs in this scenario tend to stay confined above $50 \mathrm{hPa}$, which corroborates that they do not come from lower levels in the equatorial troposphere. This either calls for an external forcing from the mid-latitudes, as for the KWs in Sect. 6.1, or an internal dynamical mechanism within the equatorial jet.

\section{Summary and discussion}

The analysis of KWs and RGWs in the lower equatorial stratosphere of the LMDz GCM shows that this model overestimates the KWs and underestimates the RGWs in comparison with the ERAI reanalysis. This result is essentially due to a dynamical filtering effect, since the zonal mean zonal wind in the LMDz lower equatorial stratosphere is always negative. On the one hand, this favours the propagation of waves with positive phase speed (like the KWs), but on the other hand this disadvantages the propagation of waves with negative phase speed (like the RGWs).

It seems that for the large-scale waves analysed, the dominant role of the background flow filtering almost completely tempers the impact of the convection scheme documented in Horinouchi et al. (2003) for instance. In the present paper, we use a LMDz simulation with a convection scheme producing a large precipitation variability (the Tiedtke, 1989, scheme)
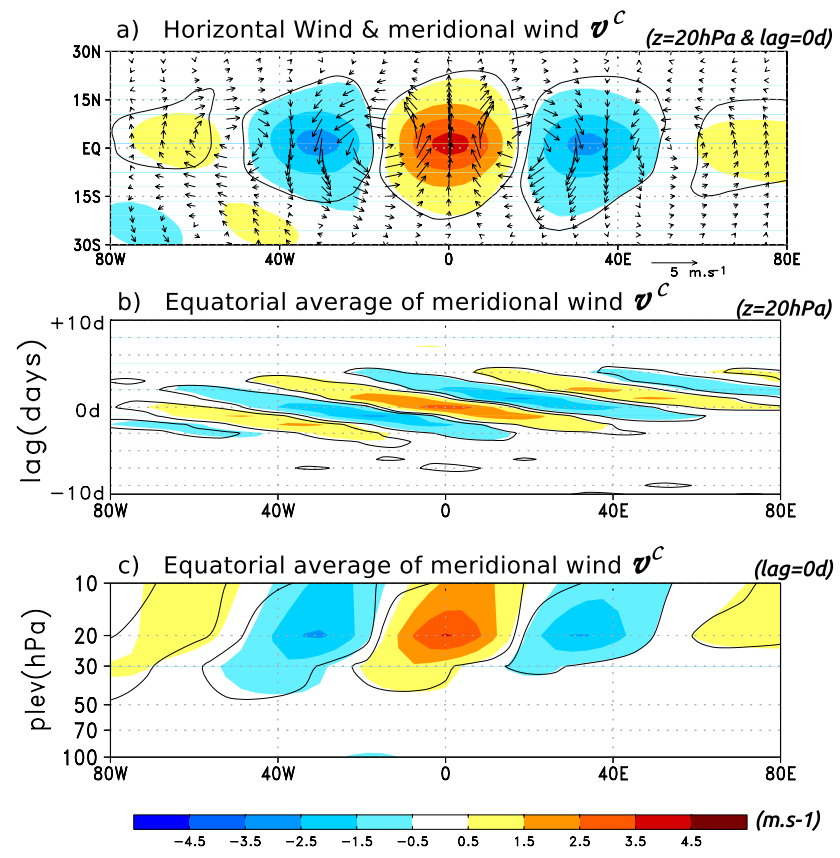

Fig. 11. RGW composites from ERAI at $20 \mathrm{hPa}$ calculated during negative phases of the $\mathrm{QBO}$ at $50 \mathrm{hPa}$ (i.e. when the zonal wind is negative at $50 \mathrm{hPa}$ and positive at $20 \mathrm{hPa}$ ). (a) Meridional wind $v^{\mathcal{C}}$ (shading) and horizontal wind $\left(u^{\mathcal{C}}, v^{\mathcal{C}}\right)$ (arrows) at $z_{p}=50 \mathrm{hPa}$ and $l=0$ day lag. (b) Hovmöller diagram of the meridional wind $v^{\mathcal{C}}$ at $z_{p}=20 \mathrm{hPa}$. (c) Longitude-altitude cross section of the meridional wind $v^{\mathcal{C}}$ averaged over the equatorial band. Shaded areas of meridional wind values are in red (blue) for positive (negative) $\left(\mathrm{m} \mathrm{s}^{-1}\right)$. The black lines delimit the $99 \%$ significant regions according to a Student $t$ test for the meridional wind.

and another one with a convection scheme producing a much smaller one (the Emanuel, 1993, scheme). Both versions resolve comparable large-scale equatorial waves in the lower stratosphere despite the tropospheric differences, which can be explained by at least two reasons. The first one follows Maury et al. (2013), who have shown that stratospheric KWs sometimes accompany the life cycle of CCKWs in the troposphere, since the CCKWs have a faster component that can reach the stratosphere under favourable vertical propagation conditions (e.g. easterly QBO phase; Lott et al., 2009). In a model without CCEWs, the forcing of large-scale waves by convection is inherently reduced. To a certain extent, one needs the CCEWs to inject variability in the spectral domain where the large-scale equatorial waves can propagate in the stratosphere. This suggests that the differences in precipitation variability are only important if they appear in the spectral space of the SEWs, but this idea could not be tested with the models used. We recall here that the planetary large-scale organisation of the convection allows adding more variability at long spatial scale and at short timescales at the same time. According to Holton (1973) for instance, it appears that this organisation may not be so significant. Note nevertheless that 
when convection is organised in a GCM, it likely better represents the heating vertical profiles, a factor which is also essential to force SEWs efficiently. The second reason might be due to the fact that the waves in the model have other sources, like for instance the subtropics and the mid-latitudes. For the KWs, we corroborated this last point by an analysis of EP fluxes, which illustrates that the LMDz sources originate rather from the subtropics and the mid-latitudes. The analysis of the RGW EP fluxes is more problematic, and could be explained by at least two reasons. Firstly, the RGWs in the model are weak and have life cycles different from those observed, and, secondly, the vertical component of the EP flux for Rossby-like waves is very small near the Equator. To circumvent these two issues, we verified that the RGWs in the model are realistic by comparing them to composites from ERAI done during easterly phases of the QBO. To show that subtropics and mid-latitude sources can also be effective for the RGWs, we used the ERAI reanalysis to make composites of the RGWs at $20 \mathrm{hPa}$ with a positive zonal wind at this level and a negative one below. In such a situation, the presence of critical levels below $20 \mathrm{hPa}$ filters the ascending waves, whereas the positive wind at $20 \mathrm{hPa}$ favours their development, and we find again substantial RGWs. These RGWs necessarily come from the subtropics and mid-latitudes, or they are internally generated.

An important point of the present paper is that subtropical and mid-latitudes sources are significant to produce SEWs. Then, in a model where the tropospheric sources are underestimated, these subtropical and mid-latitudes sources can become dominant. In this sense, the highlighted stratospheric reloading is not only important to explain the presence of RGWs above westward QBO winds, but it also reveals the significance of these alternative sources in the reanalysis products. These alternative sources explain the presence of SEWs in a model despite its underestimation of various aspects of the convection. Although our results contradict the common view that in models the equatorial waves are forced by the convection below, we recall that we only looked at the rather large-scale waves that dominate the day-to-day variability and not at the entire equatorial wave spectrum. These two limitations call for an extension of our methods to faster waves and to model versions that better simulate the CCEWs. Some of the CMIP5 models could be used to address this last issue.

Acknowledgements. We are grateful to L. Guez for his help with the model computing. We also wish to acknowledge helpful comments and feedback from E. Manzini, J. Alexander, and R. Lindzen. GPCP Precipitation data are provided by the NOAA/OAR/ESRL PSD, Boulder, Colorado, USA, from their website at http://www.esrl.noaa.gov/psd/. This work was supported by the FP7 EU projects EMBRACE (grant agreement no. 282672), the COMBINE projects (grant agreement no. 226520) and the French ANR project StraDyVariUs.
Edited by: W. Lahoz

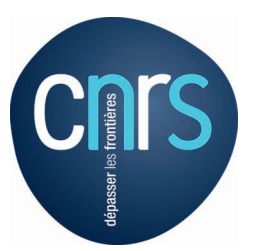

The publication of this article is financed by CNRS-INSU.

\section{References}

Adler, R., Huffman, G. J., Chang, A., Ferraro, R., Xie, P.-P., Janowiak, J., Rudolf, B., Schneider, U., Curtis, S., Bolvin, D., Gruber, A., Susskind, J., Arkin, P., and Nelkin, E.: The Version 2 Global Precipitation Climatology Project (GPCP) Monthly Precipitation Analysis (1979-Present), J. Hydrometeorol, 4, 11471167, 2003.

Alexander, M. J. and Ortland, D. A.: Equatorial waves in High Resolution Dynamics Limb Sounder HIRDLS data, J. Geophys. Res., 115, D24111, doi:10.1029/2010JD014782, 2010.

Andrews, D. G., Holton, J. R., and Leovy, C. B.: Middle atmosphere dynamics, Harcourt Brace Jovanovich, 1987.

Baldwin, M. P., Gray, L. J., Dunkerton, T. J., Hamilton, K., Haynes, P. H., Randel, W. J., Holton, J. R., Alexander, M. J., Hirota, I., Horinouchi, T., Jones, D. B. A., Kinnersley, J. S., Marquardt, C., Sato, K., and Takahashi, M.: The Quasi-biennial oscillation, Rev. Geophys., 39, 179-229, 2001.

Boville, B. A. and Randel, W. R.: Equatorial waves in a stratospheric GCM: effects of vertical resolution, J. Atmos. Sci., 49, 785-801, 1992.

Cho, H.-K., Bowman, K., and North, G.: Equatorial Waves Including the MaddenJulian Oscillation in TRMM Rainfall and OLR Data, J. Climate, 17, 4387-4406, 2004.

Dee, D. P., Uppala, S. M., Simmons, A. J., Berrisford, P., Poli, P., Kobayashi, S., Andrae, U., Balmaseda, M. A., Balsamo, G., Bauer, P., Bechtold, P., Beljaars, A. C. M., van de Berg, L., Bidlot, J., Bormann, N., Delsol, C., Dragani, R., Fuentes, M., Geer, A. J., Haimberger, L., Healy, S. B., Hersbach, H., Hólm, E. V., Isaksen, L., Kållberg, P., Köhler, M., Matricardi, M., McNally, A. P., Monge-Sanz, B. M., Morcrette, J.-J., Park, B.-K., Peubey, C., de Rosnay, P., Tavolato, C., Thépaut, J.-N., and Vitart, F.: The ERA-Interim reanalysis: configuration and performance of the data assimilation system, Q. J. Roy. Meteor. Soc., 137, 553-597, doi:10.1002/qj.828, 2011.

Eliassen, A. and Palm, E.: On the transfer of energy in stationary moutain waves, Geofys. Publ., 22, 1-23, 1961.

Emanuel, K.: A scheme for representing cumulus convection in large-scale models, J. Atmos. Sci., 48, 2313-2335, 1991.

Emanuel, K.: A cumulus representation based on the episodic mixing model: the importance of mixing and microphysics in predicting humidity, Meteor. Mon., 24, 1993.

Ern, M. and Preusse, P.: Wave fluxes of equatorial Kelvin waves and QBO zonal wind forcing derived from SABER and ECMWF temperature space-time spectra, Atmos. Chem. Phys., 9, 39573986, doi:10.5194/acp-9-3957-2009, 2009.

Ern, M., Preusse, P., Krebsbach, M., Mlynczak, M. G., and Russell III, J. M.: Equatorial wave analysis from SABER 
and ECMWF temperatures, Atmos. Chem. Phys., 8, 845-869, doi:10.5194/acp-8-845-2008, 2008.

Ern, M., Cho, H.-K., Preusse, P., and Eckermann, S. D.: Properties of the average distribution of equatorial Kelvin waves investigated with the GROGRAT ray tracer, Atmos. Chem. Phys., 9, 7973-7995, doi:10.5194/acp-9-7973-2009, 2009.

Fujiwara, M., Hasebe, F., Shiotani, M., Nishi, N., Voemel, H., and Oltmans, S. J.: Water vapor control at the tropopause by equatorial Kelvin waves observed over the Galapagos, Geophys. Res. Lett., 28, 3143-3146, 2001.

Garcia, R. R. and Salby, M. L.: Transient response to localized episodic heating in the tropics. Part II: Far-field behavior, J. Atmos. Sci., 44, 499-530, 1987.

Hendon, H. and Wheeler, M.: Some space-time spectral analysis of tropical convection and planetary scale waves, J. Atmos. Sci., 65, 2936-2948, 2008.

Hines, C. O.: Doppler spread parameterization of gravity wave momentum deposit in the middle atmosphere. Part I: Basic formulation, J. Atmos. Sol.-Terr. Phy., 59, 371-386, 1997.

Holton, J. R. and Lindzen, R. S.: An updated theory for the quasibiennial cycle in the tropical stratosphere, J. Atmos. Sci., 29, 1076-1080, 1972.

Holton, J. R.: On the Frequency Distribution of Atmospheric Kelvin Waves, J. Atmos. Sci., 30, 499-501, 1973.

Horinouchi, T., Pawson, S., Shibata, K., Manzini, E., Giorgetta, M., and Sassi, F.: Tropical cumulus convection and upward propagating waves in middle-atmospheric GCMs, J. Atmos. Sci., 60, 2765-2782, 2003.

Hourdin, F., Musat, I., Bony, S., Braconnot, P., Codron, F., Dufresne, J.-L., Fairhead, L., Filiberti, M.-A., Friedlingstein, P., Grandpeix, J.-Y., Krinner, G., LeVan, P., Li, Z.-X., and Lott, F.: The LMDz4 general circulation model: Climate performance and sensitivity to parametrized physics with emphasis on tropical convection, Clim. Dynam., 27, 787-813, doi:10.1007/s00382006-0158-0, 2006.

Jensen, E. J., Ackerman, A. S., Tabazadeh, A., and Toon, O. B.: A conceptual model of the dehydration of air due to freeze-drying by optically thin laminar cirrus rising slowly across the tropical tropopause, J. Geophys. Res., 106, 17237-17252, 2001.

Liebmann, B. and Hartmann, D. L.: Interannual Variations of Outgoing IR Associated with Tropical Circulation Changes During 1974-78, J. Atmos. Sci., 39, 1153-1162, 1982.

Liebmann, B. and Hendon, H. H.: Synoptic-scale disturbances near the Equator, J. Atmos. Sci., 47, 1463-1479, 1990.

Lindzen, R. S.: The Interaction of Waves and Convection in the Tropics, J. Atmos. Sci., 60, 3009-3020, 2003.

Lott, F. and Miller, M.: A new subgrid scale orographic drag parameterization its testing in the ECMWF model, Q. J. Roy. Meteor. Soc., 123, 101-127, 1997.

Lott, F., Fairhead, L., Hourdin, F., and Levan, P.: The stratospheric version of LMDz: Dynamical Climatologies, Arctic Oscillation, and Impact on the Surface Climate, Clim. Dynam., 25, 851-868, doi:10.1007/s00382-005-0064-x, 2005.
Lott, F., Kuttippurath, J., and Vial, F.: A Climatology of the Gravest Waves in the Equatorial Lower and Middle Stratosphere: Method and Results for the ERA-40 Reanalysis and the LMDz GCM, J. Atmos. Sci., 66, 1327-1346, doi:10.1175/2008JAS2880.1, 2009.

Lott, F., Guez, L., and Maury, P.: A stochastic parameterization of non-orographic gravity waves: Formalism and impact on the equatorial stratosphere, Geophys. Res. Lett., 39, L06807, doi:10.1029/2012GL051001, 2012.

Manzini, E. and Hamilton, K.: Middle Atmospheric Traveling Waves Forced by Latent and Convective Heating, J. Atmos. Sci., 50, 2180-2200, 1993.

Maury, P., Lott, F., Guez, L., and Duvel, J.-P.: Tropical variability and stratospheric equatorial waves in the IPSLCM5 model., Clim. Dynam., 40, 2331-2344, doi:10.1007/s00382-011-1273-0, 2013.

Pires, P., Redelsperger, J. L., and Lafore, J. P.: Equatorial atmospheric waves and their association to convection, Mon. Weather Rev., 127, 1167-1184, 1997.

Randel, W. J. and Wu, F.: Kelvin wave variability near the equatorial tropopause observed in GPS radio occultation measurements, J. Geophys. Res., 110, D03102, doi:10.1029/2004JD005006, 2005.

Ricciardulli, L. and Garcia, R.: The excitation of equatorial waves by deep convection in the NCAR Community Climate Model CCM3, J. Atmos. Sci., 57, 3461-3487, 2000.

Straub, K. H. and Kiladis, G. N.: Extratropical Forcing of Convectively Coupled Kelvin Waves during Austral Winter, J. Atmos. Sci., 60, 526-543, 2003.

Tiedtke, M.: A comprehensive mass flux scheme for cumulus parameterization in large-scale models., Mon. Weather Rev., 117, 1779-1800, 1989.

Tindall, J. C., Thuburn, J., and Highwood, E. J.: Equatorial waves in the lower stratosphere. II: Annual and interannual variability, Q. J. Roy. Meteor. Soc., 132, 195-212, doi:10.1256/qj.04.153, 2006.

Tukey, J. W.: An introduction to the calculations of numerical spectrum analysis, Spectr. Anal. Time Ser., 25-46, 1967

Wallace, J. M. and Kousky, V. E.: Observational evidence of Kelvin waves in the tropical stratosphere, J. Atmos. Sci., 25, 900-907, 1968.

Wheeler, M. and Kiladis, G.: Convectively coupled equatorial waves: Analysis of clouds and temperature in the wavenumberfrequency domain, J. Atmos. Sci., 56, 374-399, 1999.

Yanai, M. and Maruyama, T.: Stratospheric wave disturbances propagating over the equatorial Pacific, J. Meteorol. Soc. Jpn., 44, 291-294, 1966.

Yang, G., Hoskins, B., and Slingo, J.: Equatorial waves in opposite QBO phases, J. Atmos. Sci., 68, 839-862, doi:10.1175/2010JAS3514.1, 2011. 